\title{
Analisis FEM Dari Suhu HAZ Dengan Pemodelan Sumber Panas Pada Proses Butt-Joint Menggunakan MSC Marc Mentat
}

\author{
Rokki Manurung ${ }^{1}$, Septiani Silitonga ${ }^{1}$, Yohanes Hutahaean ${ }^{1}$, Charles \\ Manurung $^{2}$, Parulian Siagian', Richard AM.Napitupulu ${ }^{2}$ \\ ${ }^{1}$ Mahasiswa Prodi Teknik Mesin FakultasTeknik Universitas HKBP Nommensen \\ ${ }^{2}$ Dosen Prodi Teknik Mesin Fakultas Teknik Universitas HKBP Nommensen \\ Medan - Indonesia
}

\begin{abstract}
The success of the welding process is the occurrence of good and strong welding joints that are inseparable from the influence of the heat source. The problem that often occurs when welding is a distortion that can trigger the initial formation of cracks. By predicting the level of welding distortion beforehand, engineers can also reduce the amount of rework by reverse design and distortion margins. That is why with current technological developments it is possible to carry out simulations based on analytical solutions that are implemented through the use of software, where in this study the authors sought to model the temperature of the HAZ region in the Butt Joint process using MSC Marc Mentat. The simulation results show that the heat source is very determining the occurrence of distortion and pressure on the surface. This is caused by the phenomenon of melting and shrinkage that occurs in a short time.
\end{abstract}

Keywords : FEM Analysis, HAZ Temperature, Heat Source, Butt Joint, MSC Marc Mentat

\section{PENDAHULUAN}

Keberhasilan proses pengelasan adalah terjadinya sambungan las yang baik dan kuat. Ini tidak terlepas dari pengaruh sumber panas untuk proses peleburan logam induk untuk pembentukan sambungan las. Masalah yang sering terjadi saat pengelasan adalah distorsi [1]. Distorsi selain mengurangi kesempurnaan bentuk, juga mengurangi kekuatan sambungan yang dilas dan bisa menjadi awal terbentuknya retak.

Distorsi dalam proses pengelasan dihasilkan dari tegangan termal yang diinduksi secara termal yang ada pada sambungan las yang tidak ditahan [2]. Tiga bentuk utama distorsi yang biasanya ditemukan dalam proses pengelasan adalah: (1) penyusutan longitudinal yang terjadi dalam arah paralel dengan garis las, (2) penyusutan transversal yang berkembang dalam arah tegak lurus terhadap garis las dan (3) ) perubahan sudut karena rotasi di sekitar garis las. Konfigurasi sambungan las, input panas selama transfer, dan urutan pengelasan adalah faktor yang dapat mempengaruhi akhir distorsi. Heat-Affected Zone (HAZ) adalah area di mana struktur mikro berubah karena fusi panas selama pengelasan[3]. Ini juga menyebabkan distorsi karena ekspansi dan penyusutan yang terjadi dalam waktu singkat.

Proses pengelasan memiliki klasifikasi yang sangat luas mulai dari jenis bahan yang dilas, kondisi pengelasan apakah cair atau padat, metode, proses pengelasan, bahan pengisi dan lainnya. Proses pengelasan membutuhkan biaya yang cukup tinggi, mulai dari ketersediaan bahan, peralatan pengelasan, pengisi logam, gas pelindung dan lainnya. Jika hasil proses pengelasan tidak sempurna, tentu akan banyak biaya yang 
terbuang. Dengan melakukan perbaikan proses pengelasan, itu akan menyebabkan penundaan jadwal dan biaya tambahan yang cukup banyak. Dengan memprediksi tingkat distorsi pengelasan sebelumnya, insinyur juga dapat mengurangi jumlah pengerjaan ulang dengan cara desain terbalik dan margin distorsi.

Itulah sebabnya dengan perkembangan teknologi saat ini dimungkinkan untuk melakukan simulasi berdasarkan solusi analitis yang diimplementasikan melalui penggunaan perangkat lunak [4]. Oleh karena itu, proses pemodelan dirancang untuk dapat memperoleh pendekatan terhadap proses pengelasan aktual berdasarkan solusi analitis terkait.

\section{METODOLOGI}

Pembuatan simulasi pengelasan harus mempertimbangkan hubungan antara teknologi dalam hal hambatan yang digunakan, aspek termal, mekanik dan metalurgi dalam satu model numerik. Ini dimaksudkan untuk mendapatkan hasil simulasi yang dekat dengan keadaan asli proses pengelasan. Secara umum, membuat simulasi menggunakan Marc Mentat MSC [5] dapat dilihat pada proses berikut:

\begin{tabular}{|c|l|}
\hline \multicolumn{2}{|c|}{ Langkah } \\
\hline 1 & $\begin{array}{l}\text { Membuat geometri dan meshing } \\
\text {-membuat elemen } \\
\text {-subdivide dan expand } \\
\text {-sweeping }\end{array}$ \\
\hline 2 & Memilih sifat geometri \\
\hline 3 & Memilih sifat material \\
\hline 4 & Membuat jalur las dan pengisi las \\
\hline 5 & Membuat kondisi batas awal \\
\hline 6 & $\begin{array}{l}\text { Membuat kondisi batas akhir } \\
\text {-beban titik } \\
\text {-perpindahan tetap } \\
\text {-fluks volume pengelasan }\end{array}$ \\
\hline 7 & Loadcase \\
\hline 8 & Pengerjaan \\
\hline 9 & Hasil interpretai \\
\hline
\end{tabular}

Gambar 1. Diagram Alir Umum Prosedur menggunakan Simulasi

\subsection{Deskripsi Geometris dan Material}

Gambar 2 menunjukkan ilustrasi skematik dari model geometri, yang memiliki dimensi pelat $30 \times 50 \mathrm{~mm} \times 2$ dengan V Groove, ketebalan pelat adalah $2 \mathrm{~mm}$, yang ditugaskan untuk menghasilkan las satu sisi. Dalam simulasi ini, geometri disatukan menggunakan manik las satu-lulus. 


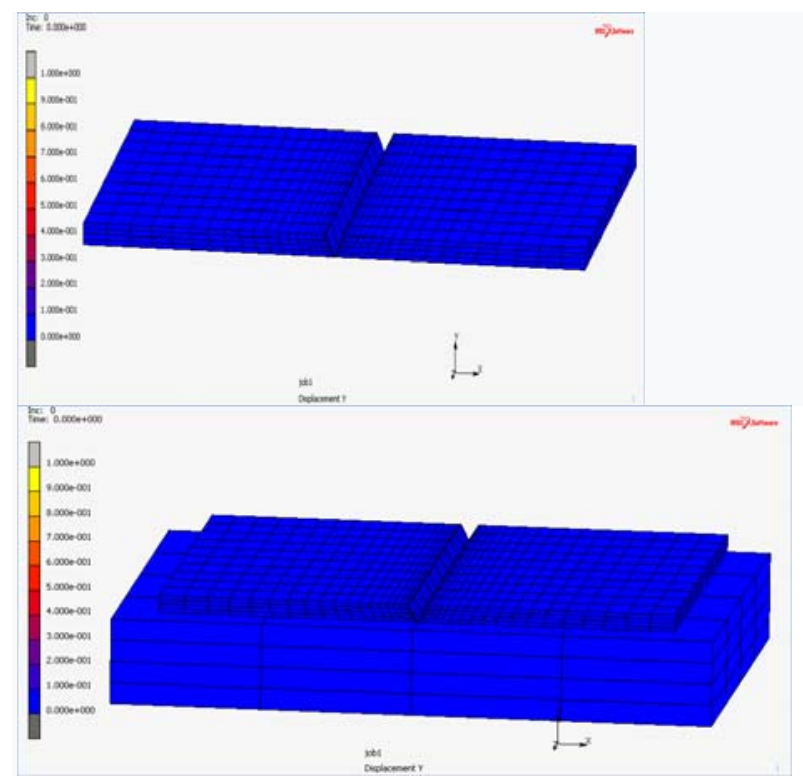

Gambar 2. Model elemen tak terbatas dari 3D-Solid V Groove Butt-joint tanpa meja (kiri) dan 3D-Solid V Groove Butt-joint dengan meja (kanan)

Dalam simulasi ini, Aluminium(Asm Al 21) dan Stainless Steel (X10Cr13-1) dipilih sebagai bahan untuk pelat sambungan-T dan bahan pengisi. Sifat fisik material stainless stell ditunjukkan pada Gambar 3. Gambar ini menunjukkan bahwa material yang ditugaskan untuk simulasi FEM memiliki variabel tergantung suhu. Sedangkan Aluminium tidak memiliki sifat fisik Material melalui Grafik.

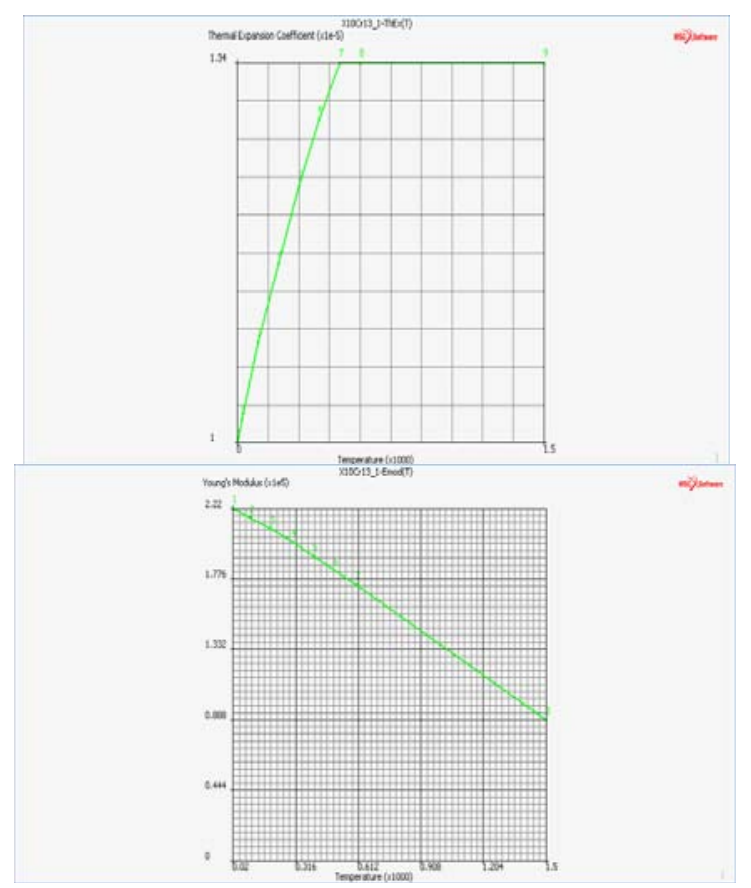




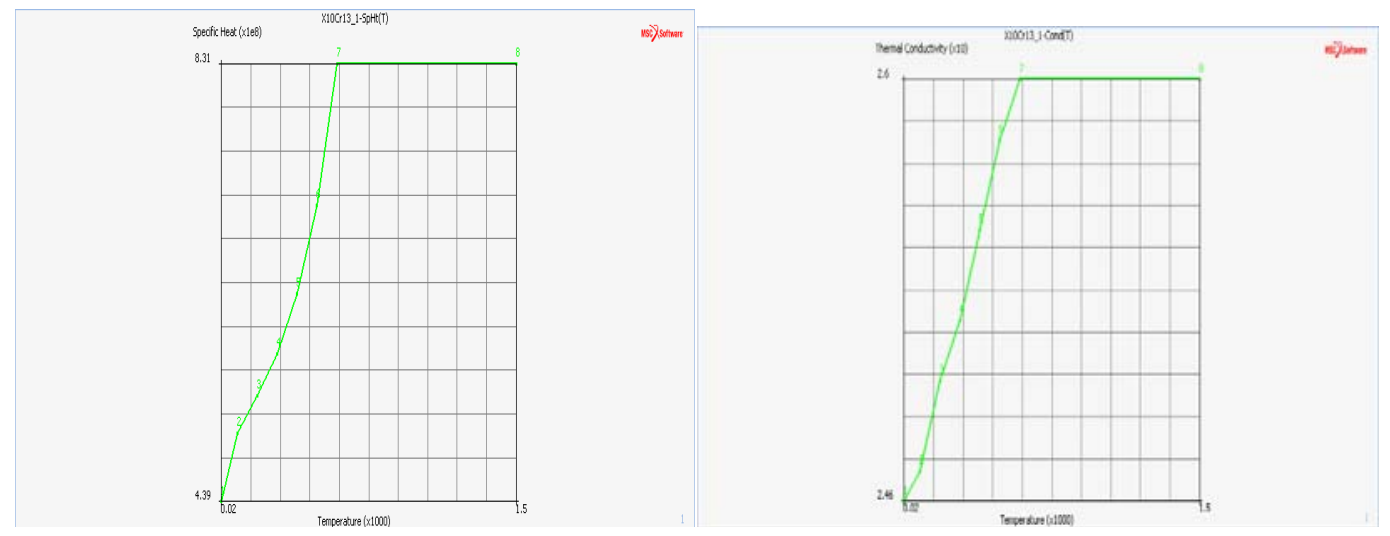

Gambar 3. Sifat termo-fisik yang bergantung pada suhu dari Stainless Stell (X10Cr13-1): (a) Koefisien Ekspansi Termal, (b) Modulus Young, (c) Panas Spesifik dan (d) Konduktivitas Termal

\subsection{Menugaskan Badan Kontak dan Interaksi}

Dalam Simulasi FEM ini, Badan Kontak ditetapkan sebelum menentukan interaksi kontak semua elemen. Elemen dalam simulasi ini adalah 2 Pelat, Pengisi Las dan Tabel. Jenis kontak yang tidak dapat diubah ditugaskan untuk pengelasan dan pengisi sementara jenis kontak yang kaku ke meja. Ini berlaku untuk model Shell dan Solid. Dalam simulasi FEM ini, tipe kontak yang dapat dideformasi dipengaruhi oleh hasil simulasi setelah pekerjaan ditetapkan, perubahannya dapat dilihat secara implisit selama analisis termomekanis di mana transformasi permukaan terjadi saat menjalankan hasil. Sementara kontak kaku cenderung memiliki permukaan yang lebih statis selama eksekusi karena mode tubuh kaku didefinisikan sebagai terjemahan bebas atau rotasi benda tanpa mengalami deformasi internal yang signifikan. Ada dua jenis kontak interaksi yaitu "Touching / T" dan "Glued / G". Dua kontak ini tersedia di MSC Marc / Mentat terletak di bagian badan kontak.

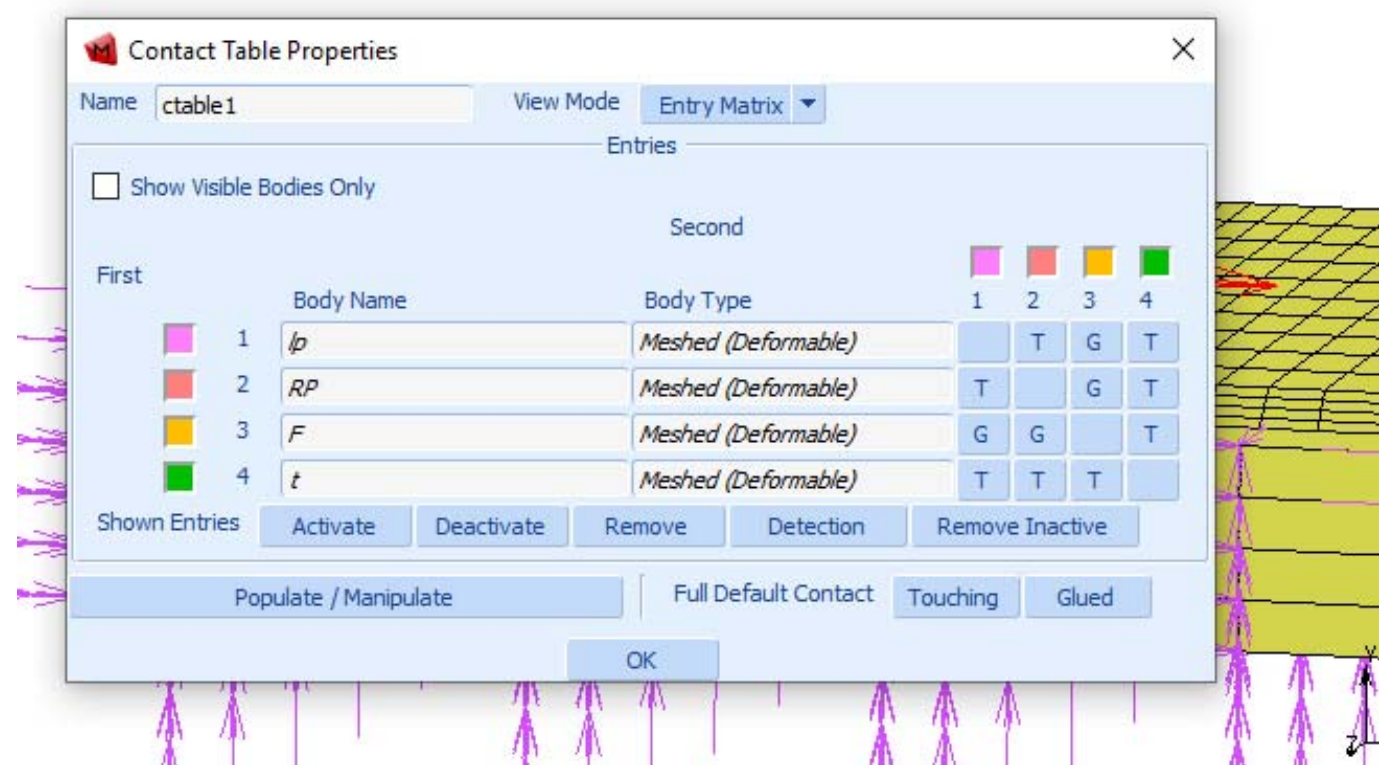

Gambar 4. Interaksi kontak elemen (G: Terpaku, T: Menyentuh) 


\subsection{Ketentuan Awal dan Batas}

Kondisi awal dan batas model elemen hingga meliputi termal dan kondisi batas mekanis, di mana pertimbangan utama dari batas termal kondisinya adalah radiasi panas, konduksi panas dan pendinginan termal konveksi. Di dalam simulasi, analisis ikatan dibagi menjadi analisis termal dan struktural. Itu parameter termomekanis ditentukan pada setiap bagian dari kondisi batas pada keduanya model shell dan solid.

Analisis struktural untuk bounndary ini terdiri dari perpindahan tetap dan struktural beban titik. Keduanya adalah fitur analisis struktural yang disediakan oleh MSC Marc / Mentat.

Kondisi batas termal dalam simulasi ini adalah thermal face film dan thermal volume weld flux. Thermal face film diimplementasikan dalam prosedur yang sama untuk keduanya model shell dan solid dari $V$ Groove Butt-Joint sementara thermal volume flux memiliki salah satu dari keduanya model berbeda satu sama lain. Dalam hal ini, panas ke sekitar filler las (sekitarnya face weld flux) dianggap tidak ada apa-apa. Jumlah input panas yang digunakan adalah $100000 \mathrm{~mm} / \mathrm{s}$ dan jumlah efisiensi yang digunakan adalah 0.8. Kecepatan kecepatan las cocok dengan parameter eksperimental yaitu $6 \mathrm{~mm} / \mathrm{s}$ yang nantinya akan disertai dengan pengelasan jalur dan penugasan pengisi. Kuat arus (I); dan tegangan (V) adalah dipertimbangkan di bawah persamaan kekuasaan. Kecepatan perjalanan yang ditetapkan (v) didasarkan pada ideal kecepatan pengelasan untuk bahan ini menggunakan one-pass V-Groove Butt-joint.

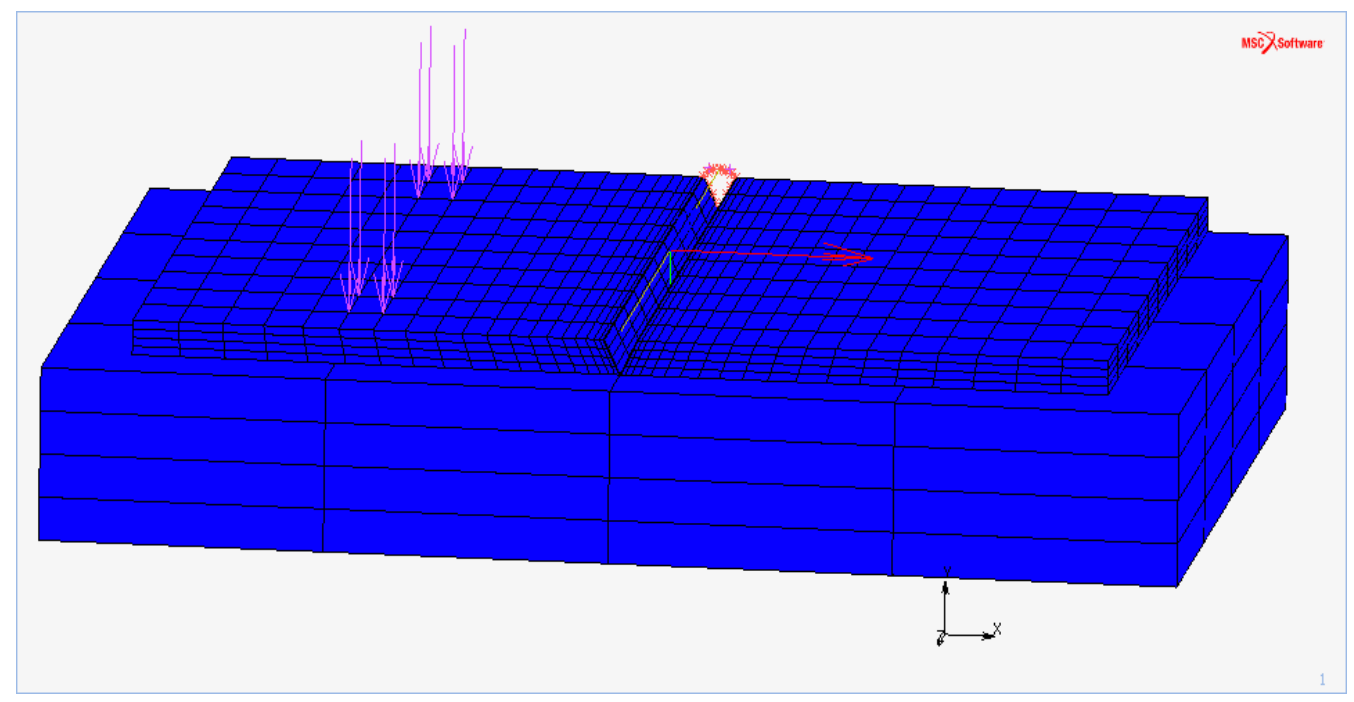

Gambar 5. Menutup posisi kondisi batas struktural

Dalam MSC Marc / Mentat, pembangkit sumber panas diatur sambil menetapkan kondisi batas volume weld flux dalam analisis termal. Model Elipsoid Ganda Goldak dipilih sebagai model sumber panas untuk simulasi ini. Model Double Ellipsoid yang sebagian besar digunakan untuk mewakili panas yang dibuat oleh obor dalam pengelasan GMAW. Double Ellipsoid berarti bahwa sumber panas terdiri dari dua daerah elips, satu di depan busur dan satu di pusat. Z $>0$ dan yang lainnya di belakang pusat busur adalah Z $<0$ [4]. Gambar 6 mengilustrasikan model Ellipsoid Ganda Goldak. 


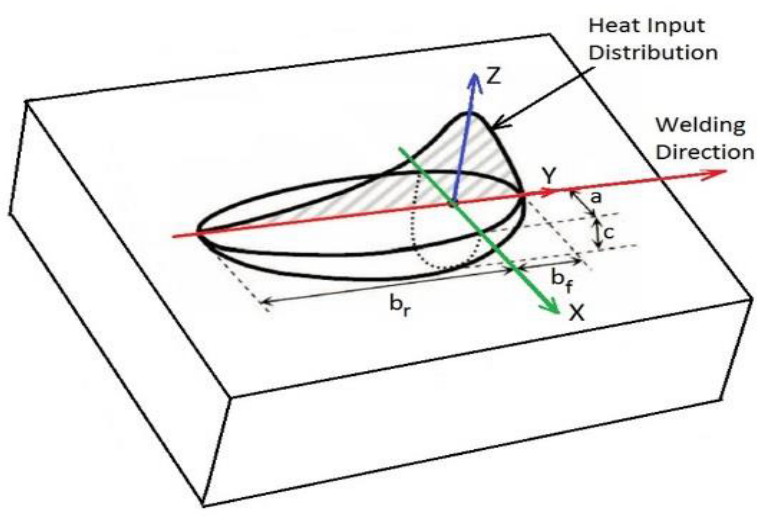

Gambar 6. Ilustrasi Model Sumber Panas Ellipsoid Ganda

Tabel 1. Dimensi Sumber Panas dalam Simulasi FEM Arah Sumber Panas

\begin{tabular}{|c|c|}
\hline Dimensi & Nilai \\
\hline Lebar(mm) & 4 \\
\hline kedalaman(mm) & 4 \\
\hline Panjang ke depan(mm) & 3 \\
\hline Panjang belakang(mm) & 4 \\
\hline Power(watt) & 100000 \\
\hline kecepatan(mm/s) & 6 \\
\hline
\end{tabular}

\section{HASIL DAN DISKUSI}

Dari hasil simulasi, dapat diketahui bahwa parameter yang lebih baik harus dilakukan pada eksperimental. Ini disimpulkan berdasarkan perbandingan terlihat antara 2 parameter terbaik dari parameter yang disimulasikan. Gambar yang ditunjukkan di bawah ini adalah perbandingan Temperatur, Perpindahan dan Efektif Variabel stres pada Peningkatan diamati untuk masing-masing node yang sama.

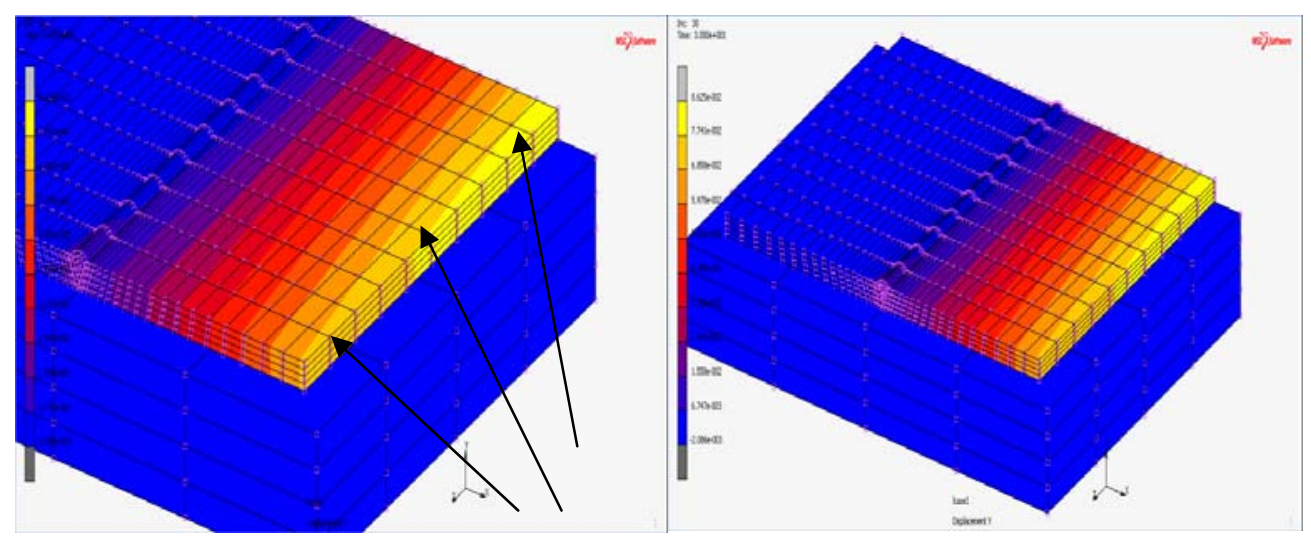

Gambar 7. Collecting temperature data stainless stell 


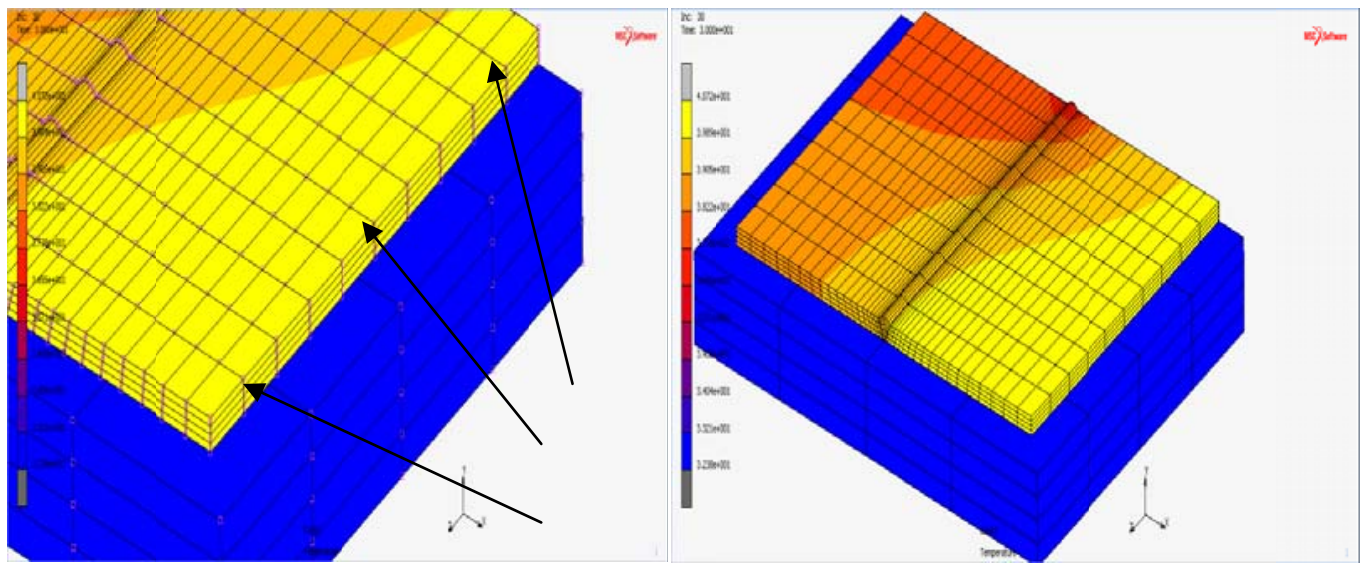

Gambar 8. Collecting temperature data aluminium

Dari Gambar 7 dan 8, kita dapat melihat perbedaan dalam kondisi suhu, perpindahan dan stres efektif diambil pada simpul yang sama di wilayah HAZ. Perbandingan hasil simulasi dari gambar di atas juga dapat dilihat pada kurva berikut:

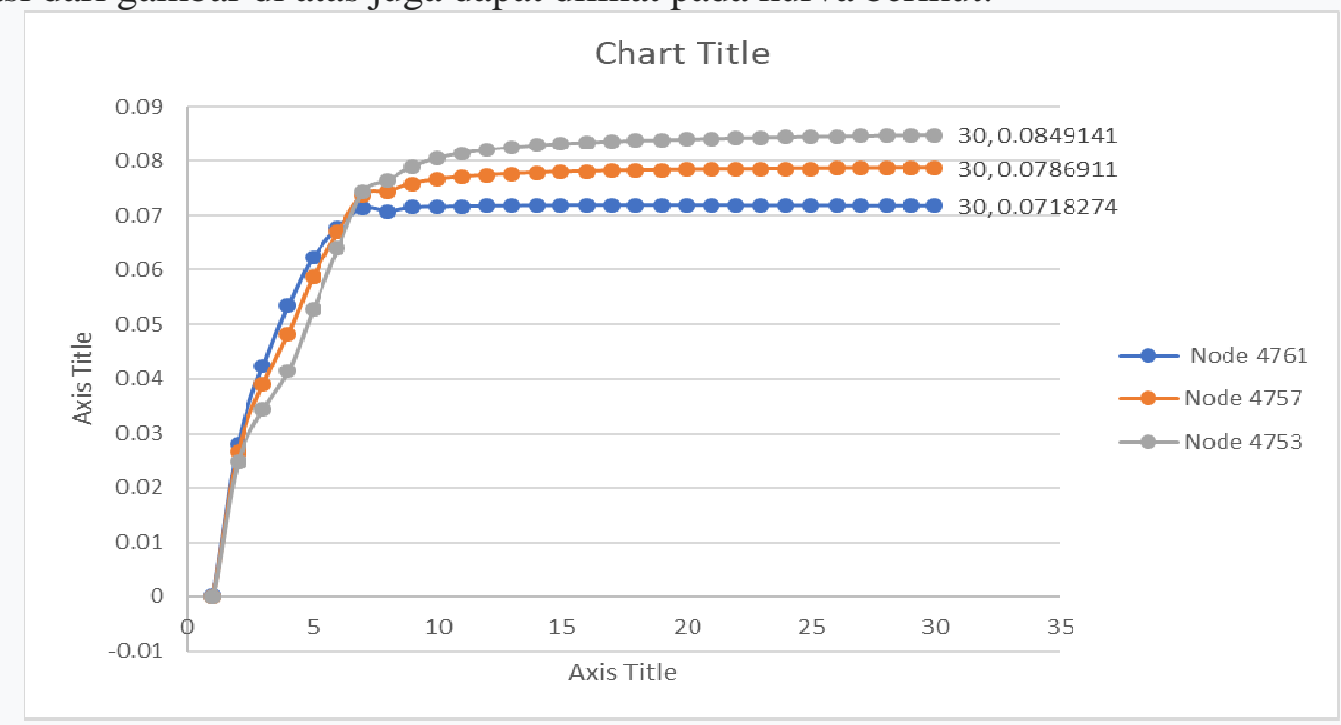

Gambar 9. Kurva stainless stell

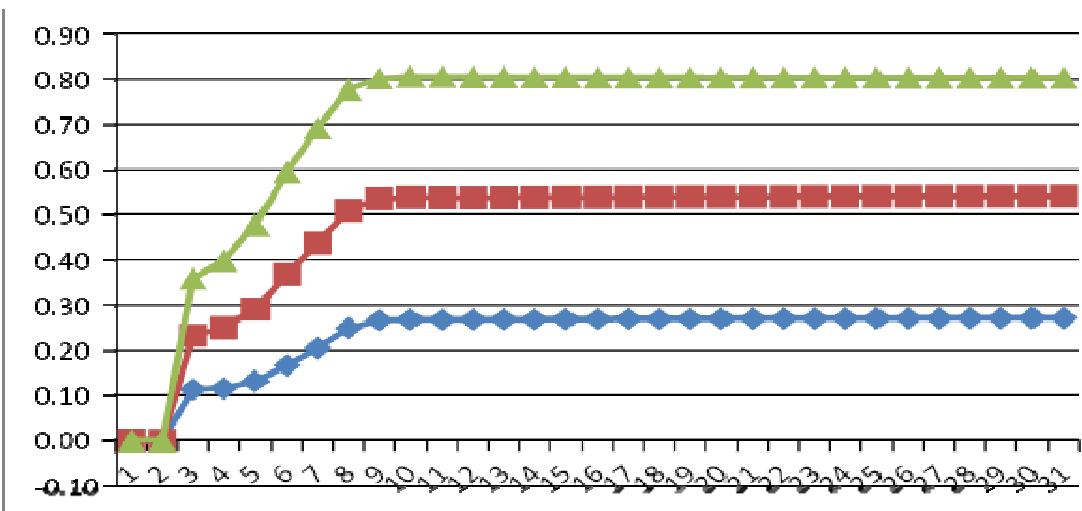

Gambar 10. Kurva Alluminium 
Dari gambar di atas dapat dilihat bahwa sumber panasnya sangat menentukan terjadinya distorsi dan tekanan pada permukaan. Ini disebabkan oleh fenomena mencair dan susut yang terjadi dalam waktu singkat. Di bidang utama pengelasan seperti las.

\section{KESIMPULAN}

Melalui Metode Elemen Hingga, dapat disimpulkan bahwa pemodelan dan simulasi telah berhasil dilakukan dan hal-hal berikut dapat disampaikan:

1. Penggunaan perangkat lunak elemen hingga sangat membantu dalam menyelesaikan untuk mendapatkan pengelasan yang lebih baik parameter dibandingkan dengan metode coba-coba dalam proses pengelasan yang sebenarnya.

2. Dengan menggunakan perangkat lunak, efisiensi dan efektivitas pekerjaan lebih baik, ini disebabkan oleh harga material yang relatif mahal dan waktu kerja terbatas hanya dilakukan di bengkel las Indonesia.

3. Dengan hasil parameter pengelasan yang diperoleh, terutama di suhu distribusi, sifat mekanik yang akan dihasilkan dari proses pengelasan bisa diramalkan. Kondisi suhu berkontribusi pada perubahan struktur mikro, keduanya rekristalisasi dan pertumbuhan butir. Pertumbuhan butir ke tingkat yang tidak diinginkan akan mengurangi sifat mekanik menurut rumus Hall-Petch tentang hubungan diameter butir untuk menghasilkan kekuatan

\section{DAFTAR PUSTAKA}

1. R. A. M. Napitupulu, S. L. M. H. Simanjuntak, C. Manurung, C. Hutabarat, S. Sitompul, and J. N. Aoh, "Friction stir welding of aluminium alloy 6061-t651," IOP Conf. Ser. Mater. Sci. Eng., vol. 508, p. 012064, 2019.

2. K. P. Prajadhiana et al., "Comparative distortion analysis of welded T-Joint between 2D-shell and 3D-solid element using FEA with experimental verification," J. Mech. Eng., vol. 5, no. Specialissue2, pp. 99-115, 2018.

3. Charles S.P. Manurung et.al., FEM analysis of the HAZ temperature by heat source modeling on butt joint process using msc marc mentat, IOP Conf. Ser.: Mater. Sci. Eng. 725, 012009, 2020

4. D. Sebayang et al., "Numerical simulation of distortion and phase transformation in laser welding process using MSC Marc/Mentat,” IOP Conf. Ser. Mater. Sci. Eng., vol. 453, no. 1, 2018.

5. MSC Software, "Volume A: Theory and user information," MSC.Software Corp., 2016. 